\title{
R. ADELL ARGILÉS (coord.). ¿Dónde están las llaves? El movimien- to okupa: prácticas y contextos sociales. Madrid, Los Libros de la Catarata, 2005.
}

\section{Buscando llaves, abriendo puertas}

El libro ¿Dónde están las llaves? El movimiento okupa: prácticas y contextos sociales que coordinan Ramón Adell y Miguel Martínez nos adentra conscientemente en las dificultades que se le presentan al investigador o investigadora a la hora de analizar un movimiento social, especialmente aquellos que se dedican continuamente a "romper moldes», entendiendo por moldes tanto los presupuestos teóricos de la persona que los analiza como los valores, los hábitos y las estructuras sociales contra los que deciden enfrentarse los activistas.

Por una parte, esta dificultad viene acentuándose con el surgimiento en los 60 de los nuevos movimientos sociales (pacifismo, feminismo, ecologismo, etc.) como nos indica Tomás Rodríguez Villasante en el prólogo del libro. Estos movimientos irrumpen, particularmente en Occidente, a la búsqueda de nuevas formas y canales de expresión social y política. Por tanto, tienen ante sí muchos frentes en los que pueden desplegar su actividad, que trasciende la mera protesta o el mantenimiento de reivindicaciones puntuales frente a un conflicto. Uno de esos frentes consiste en la alteración cotidiana de las identidades de sus participantes, que crean y renegocian sus formas de intervenir en la arena social, así como sus referencias vitales (hábitos de ocio y consumo, expresiones culturales, problematización de cuestiones de autoridad, sexuales o laborales, etcétera). Otro de los campos donde dejarán huella será la propia ciudadanía a la que se dirigen o, como en el caso del movimiento por las okupaciones, a la que abren sus puertas para pasar una película, organizar una asamblea sobre planes urbanísticos de los ayuntamientos o informar sobre la última directiva de la Organización Mundial del Comercio. Por último, todo movimiento social se enfrenta a unas autoridades con el propósito de alterar las agendas políticas de las redes públicas.

Aparte de los múltiples frentes, estos movimientos sociales rehúyen de forma explícita ser etiquetados a gusto del sociólogo o socióloga que los observa, como nos informan Tomás Rodríguez Villasante y los coordinadores del libro en su introducción al mismo. Esto es especialmente relevante para el caso de las redes sociales analizadas, pues las prácticas que se promueven desde la «okupación» tienen múltiples motivaciones (denuncia de la especulación inmobiliaria; consecución de 
vivienda, centros sociales o de espacios feministas; desarrollo de proyectos ecológicos en el campo o consecución de tierras para su cultivo) y puestas en escena (en la ciudad o en el campo, conformando redes estables o una agregación más informal de individuos, como denuncia concreta o a la búsqueda de un espacio social que sea referencia política en el barrio, con distinto grado de enfrentamiento con las autoridades en función de la posición de éstas). La diversidad existente y la debilidad de los lazos que ponen en contacto, si es que lo hacen, estas experiencias, junto con la alta creatividad de cada una de estas iniciativas impulsa a sus participantes a rehuir homogeneizaciones que consideran impuestas -en un movimiento de influencias libertarias notables - y a fomentar el reconocimiento de la singularidad de cada acción que se pone en marcha.

Por otra parte, la dificultad a la que se enfrenta todo libro de análisis de movimientos sociales viene del lado de sus realizadoras y realizadores: ¿cómo conjugar un análisis externo con la, a mi juicio, necesaria visión desde dentro de estos movimientos tan huidizos y $\tan$ cotidianos sin caer en la redacción de un panfleto a favor de los mismos?, ¿desde qué perspectiva de las múltiples existentes hemos de adentrarnos en el estudio de la actividad de estos fenómenos sociales? Estos grandes interrogantes están presentes en el punto de partida del libro, como recogen Ramón Adell y Miguel Martínez en la introducción, y hacen por ello posible un acercamiento profundo y sincero, a la vez que abierto a nuevas reinterpretaciones, a la complejidad en la que se desenvuelven las redes de okupación.

La respuesta dada por los autores del libro es, en mi opinión, altamente satisfactoria. Para adentrarnos en las prácticas del movimiento okupa, contaremos en primer lugar con reflexiones y análisis sociológicos que no surgen desde el pro- pio movimiento, sino que tratan de situarlo en un contexto europeo -más allá por tanto de la singularidad que reclamarían muchos de sus participantes-y parte de una serie de perspectivas y conclusiones analíticas que han dado su fruto en el estudio de los nuevos movimientos sociales (estructuras de oportunidad política, teorías constructivistas). Estas perspectivas contarán con una observación participante que dota al libro de nuevos enfoques (como la relación de estos movimientos con las protestas «alterglobalización» y las nuevas tecnologías como internet y su distanciamiento de los nuevos movimientos sociales) que trascienden estas escuelas más temáticas y poco dadas en sus comienzos a vincular perspectivas y familias de movimientos sociales. A su vez, la observación participante se conjuga con la constatación empírica para, en este caso, dotar de credibilidad y alcanzar una mejor comprensión de las revoluciones cotidianas que se alcanzan o que se persiguen por sus activistas (cambios en las formas de protesta, recreación de una «kontrakultura urbana»).

Con respecto a la pluralidad de enfoques existentes, los diferentes autores irán recogiendo y estableciendo nexos entre distintos presupuestos y perspectivas del análisis de los movimientos sociales. Servirán como lazo de unión de estos «conjuntos de acción» tan heterogéneos unos mínimos hilos conductores que irán abordándose desde diferentes planos (macro y micro, cultural y político, individual y colectivo). En cuanto al contenido de estas movilizaciones, se situará como una constante la búsqueda de alternativas de vida $-\mathrm{y}$ por ello de participación política- frente a una «globalización» que rompe vínculos vitales (laborales, familiares, de hábitat estable) con extremada facilidad y que construye unas agendas políticas a espaldas de la ciudadanía en muchos casos (privatizaciones, diseños 
urbanísticos, desmantelamiento de políticas sociales). Por lo que respecta a la forma con la que se ponen en pie y se visibilizan estas protestas, la reapropiación de espacios y de pautas culturales (a través de procesos asamblearios y de autogestión) y la construcción de redes policefálicas y muy abiertas aparecen como señas de identidad que son observadas desde distintos ángulos.

La multitud de miradas sociológicas se irá sucediendo en torno a las cuatro cuestiones clave en el análisis de este tipo de acción colectiva: los porqués (sociales e individuales) de su irrupción, el cómo construyen respuestas (discursos, coordinaciones, protestas) y se enfrentan a los conflictos sociales, el cuándo tiene lugar la masiva difusión de sus repertorios de acciones y las razones para ello (alianzas, contexto político y cultural, ciclos de protesta, el acceso a recursos económicos y tecnológicos) y, finalmente, el para qué, es decir, la evaluación de cómo esta acción colectiva ha afectado a su entorno (imaginarios sociales y agendas mediáticas, políticas públicas, formas de actuar y de representarse el mundo por parte de las personas activistas).

Con respecto a los porqués, los artículos de Pruijt y Miguel Martínez nos explicarán respectivamente las raíces europeas y el contexto urbano en el que se han desenvuelto buena parte de estas prácticas, que, si bien se iniciaron desde la simple reclamación de viviendas, posteriormente han ido adquiriendo para amplios sectores una utilidad en términos de rebeldía social frente a formas tradicionales de concebir la política.

En cuanto al cómo, Ramón Adell hace un detallado y empíricamente contrastado examen de cómo han ido evolucionando las formas de acción y los discursos desde las redes de okupación.

El contexto que delimita el cuándo de la protesta aparece abordado de forma general en el artículo de Tomás Herreros, quien sostiene que estas redes de okupación son "movimientos madrugadores" en los que han socializado y experimentado nuevas herramientas de acción parte de las y los integrantes de las redes «alterglobalización». Javier Alcalde se ocupará de cómo los medios de comunicación abordan la problemática «okupa». Virginia Gutiérrez nos detallará los encuentros y desencuentros que se dan entre el movimiento okupa y otras redes muy cercanas, como es el caso del movimiento vecinal. Igor Sádaba y Gustavo Roig nos ofrecen una visión muy madurada y por ellos vivida de cómo estos movimientos se han servido de internet para construir sus redes o sus formas de construir espacios «liberados», incluso en terrenos virtuales. Finalmente, Jaume Asens nos sitúa en el centro del conflicto público de estas redes: la represión que se inicia en 1996 con la tipificación penal de estas prácticas.

Por último, y con respecto al impacto de estos movimientos sociales, pero también relatándonos de qué manera recrean sus referencias vitales y sociales (de acción, de identidad, como desafío de códigos patriarcales y autoritarios), Marta Llobet nos adentra en la construcción de una «kontrakultura» social, Marina Marinas nos ofrece un análisis de cómo las okupaciones se utilizan para derribar los muros del género y Robert Gonzàlez estudia de qué manera las prácticas de la okupación han afectado a políticas públicas en los terrenos de juventud y vivienda.

El libro parte de la complejidad del fenómeno y de la necesidad de proponer múltiples miradas para abordar el estudio de las redes de okupación. No se considera un «libro cerrado". Por ello, entiendo que el estudio tiene a la vez una intención de recopilar esta multiplicidad de miradas hacia el pasado, así como de servir de punto de partida para análisis más «compactos» -con una línea argu- 
mental más gruesa, si llegare a ser posible, y situándose en el actual ciclo de movilizaciones mundial- y que profundicen en las líneas que ya se recogen en el trabajo.

Efectivamente, no existen llaves para descifrar plenamente estos movimientos sociales, y especialmente el movimiento de las okupaciones. Pero sí se puede, como demuestra el libro, abrir puertas para entender desde perspectivas más glo- bales (que conectan múltiples problemáticas y que se desenvuelven con comodidad y con gran motivación tanto en terrenos locales como a través de redes internacionalistas) estos fenómenos sociales que tienen mucho que ver con las protestas y las respuestas que se están dando actualmente a la llamada «globalización neoliberal».

Ángel Calle 